Article

\title{
Reversibility and Durability as Potential Indicators for Circular Building Technologies
}

\author{
Ernesto Antonini ${ }^{1}\left[\right.$, Andrea Boeri ${ }^{1}$, Massimo Lauria ${ }^{2}$ and Francesca Giglio ${ }^{2, *}$ (D) \\ 1 Department of Architecture, University of Bologna, 40136 Bologna, Italy; ernesto.antonini@unibo.it (E.A.); \\ andrea.boeri@unibo.it (A.B.) \\ 2 Department of Architecture and Territory dArTe, Mediterranea University of Reggio Calabria, \\ 89124 Reggio Calabria, Italy; mlauria@unirc.it \\ * Correspondence: francesca.giglio@unirc.it; Tel.: +39-0965-1697131
}

Received: 29 July 2020; Accepted: 13 September 2020; Published: 16 September 2020

\begin{abstract}
According to the Circularity Gap Report 2020, a mere 8.6\% of the global economy was circular in 2019. The Global Status Report 2018 declares that building construction and operations accounted for $36 \%$ of global final energy use and $39 \%$ of energy-related carbon dioxide $\left(\mathrm{CO}_{2}\right)$ emissions. The Paris Agreement demands that the building and construction sector decarbonizes globally by 2050 . This requires strategies that minimize the environmental impact of buildings and practices extending the lifecycle of their constituents within a circular resource flow. To ensure that effective measures are applied, a suitable method is needed to assess compliance in materials, processes, and design strategies within circular economy principles. The study's assumption is that synthetic and reliable indicators for that purpose could be based on reversibility and durability features. The paper provides an overview of building design issues within the circular economy perspective, highlighting the difficulty in finding circular technologies which are suitable to enhance buildings' service life while closing material loops. The results identify reversibility and durability as potential indicators for assessing circular building technologies. The next research stage aims to further develop the rating of circularity requirements for both building technologies and entire buildings.
\end{abstract}

Keywords: Circular Design; circular technologies; reversibility; durability; circular potential; indicators; service life; closed material loops

\section{Introduction}

Global demand for materials increased over the past century, driven by the steady economic growth of the Organisation for Economic Co-operation and Development Countries (OECD), the industrialization of emerging economies, and the expansion of the world population [1].

According to the Circularity Gap Report 2020, only 8.6\% of the world economy is circular. This means that only $8.6 \%$ of the minerals, fossil fuels, metals, and biomass which enter it every year are subsequently reused. This share had been estimated at $9.1 \%$ in the 2018 Report; a fall of $0.5 \%$ in two years [2].

Since the global use of raw materials has increased by almost double the population growth rate, the OECD finds that efficient use of resources and furthering the transition to a circular economy can help not only material supply security but also improve environmental and economic outcomes as well. There is no single accepted definition of the circular economy, but it is often defined as the emerging opposition to the so-called linear economy (take-make-dispose model). The most recognized definition comes from the Ellen MacArthur Foundation: it "is restorative and regenerative by design and aims to keep products, components, and materials at their highest utility and value at all times," aiming to decouple economic growth from resource consumption [3]. The aim of design for a circular economy 
is to maintain product integrity over multiple use cycles (for instance, through repair, refurbishment, and remanufacturing) and to focus on closing loops (through recycling), while at the same time building economically viable product-service systems [4].

The UN Sustainable Development Goals and the 2015 Paris Climate Agreement target to increase the circular share of the economy by addressing several key actions on energy and material efficiency improvement.

In particular, and as far as the building sector is concerned, the Paris Agreement demands global decarbonization by 2050, with the aim of avoiding the impact of a +2 degree rise in temperature. With this objective in mind, the Global Status Reports published annually by the UN Environment, the International Energy Agency (IEA), and the Global Alliance for Buildings and Construction (GABC) focus on the state of the building and construction sector and tracking the progress of this sector. In particular, in 2018, the report highlighted that "building construction and operations [account for] $36 \%$ of global final energy use and 39\% of energy-related carbon dioxide (CO2) [emissions]" [5].

Around 374 million tons of construction and demolition waste (C\&DW) were generated in 2016, making it the largest waste stream in the EU by weight of which the mineral content formed the largest fraction [6].

Data demonstrate that the construction industry has traditionally followed a linear economy process.

This has led to a number of challenges requiring solutions through those enabling factors which can maximize value from the circular economy by applying Circular Business Models (CBMs) in the current value chain.

By adopting circular economy business models, the focus will shift to sustainable sourcing, maintaining material productivity over the lifecycle of developments, and reducing loss in non-renewable materials. This will produce financial, social, and environmental benefits [7].

The European Commission emphasizes the role of design in the EU action plan for the circular economy: "better design can make products more durable or easier to repair, upgrade or remanufacture" (European Parliament Research Service [8]).

To implement these strategies, criteria and indicators are needed to assess the circular potential of those technical options which can be adopted and to assess their efficiency.

The concepts of reversibility and durability, as highlighted in the current sector literature, are already widely covered in all Circular Design strategies, including those addressing the construction sector in particular.

Reversibility is the property of a process, a system, or a device to return it to the original state. This means that the transformations performed to make that object suitable for a specific purpose can be reversed, restoring previous conditions to the transformation implemented. Meanwhile durability is the property of a process, a system, or a device to maintain its capability to provide the features it is designed for overtime. Both notions are thus closely time-related but by an antithetical relation, as the first implies transience, and the second permanence.

Nevertheless, no clear definitions are yet available to link concepts related to Circular Design strategies to indicators which are suitable to measure the circular economy and, specifically, circular building technologies.

This creates a barrier which obstructs the need for extending the circularity assessment of construction technologies to the whole functional complexity of an entire building (circular building) from properly considering any further performance involved.

For this reason, the study focuses on the notion of circular building technologies that embody the need to redefine how materials, processes, and products are designed and used within circular economy principles [9].

This leads to a focus on reversibility and durability as possible, suitable indicators for integrating a definition of circular building which complies with circular economy principles. 
This paper addresses those topics through a methodology structured into three parts. The first part provides an overview of building design issues from the circular economy perspective. The second part highlights, from the literature overview conducted, the difficulties in finding circular technologies suitable for enhancing a building's service life and closing material loops. Reversibility and durability are then proposed in the third part (results) as possible indicators for assessing the circular potential of building technologies, while the next research stage is aimed at further developing the rating of both construction materials and whole buildings through the application of Circular Design strategies.

The study's assumption was that reversibility and durability can represent reliable indicators for this purpose as they integrate both quantitative aspects related to circular technologies and qualitative aspects referring to the service life and closed loop.

The study aimed to identify reversibility and durability as possible, synthetic, and reliable indicators to assess the compliance of building technologies with circular economy principles.

The expected research contribution was to integrate the advancement and dissemination of knowledge of tools for the application of Circular Design to the building sector.

The result may be useful for a further, undeveloped future phase of the study in which the indicators could enhance the principal sustainability rating systems referring to the circularity requirements of both building technologies and entire buildings.

\section{Designing Buildings in the Context of the Circular Economy: An Overview}

\subsection{From Building Design Principles Applying the Circular Economy to Circular Design}

Through the European Green Deal [10], the European Commission has prompted the application of the principles of the circular economy and resource efficiency in the construction sector aimed at reducing the use of primary natural resources in the future. As summarized in the document "Circular Economy-Principles for Buildings Design" (2020) [11], within the Construction 2020 strategy [8] and in line with the upcoming new circular economy action, the European Commission focuses on a set of principles for sustainable building design, designed to prevent and reduce construction and demolition waste while facilitating the reuse and recycling of building materials. This is expected to mitigate the environmental impact of building and reduce life cycle costs.

The measures address all the construction industry actors contributing to the building value chain, including building users; investors, developers, and insurance providers; design teams (engineering and architecture of buildings); manufacturers of construction products; contractors and builders; facility managers and owners; deconstruction and demolition teams; governmental and local regulation authorities.

The document refers to "Level(s)" - the Common European Framework of Sustainability Indicators-and the EC Communication [12] "A new Circular Economy Action Plan for a cleaner and more competitive Europe", which establishes a new comprehensive strategy for the sustainability of the built environment, material efficiency, and climate impact reduction. In particular, the document contributes to Level(s) Macro-objective 2: "Resource efficient and circular material life cycles" which targets waste reduction, material use optimization, and the reduction of environmental impact throughout the life cycle through suitable design choices. To reach this macro-objective, specific measures are envisaged called "life cycle tools: scenarios for building lifespan, adaptability and deconstruction". For building design, the general principles suggested are:

1. Durability: focus the building and planning of basic living services on a medium-to-long lifespan of the major building elements, while also considering their maintenance and replacement cycles;

2. Adaptability: extend the service life of whole buildings, either by facilitating the continuation of their original use or possible future changes performed by replacement and refurbishment;

3. Reduce waste and facilitate high-quality waste management: facilitate the future circular use of dismissed building elements, components, and parts, paying special attention to both reduced waste production and exploiting the potential for reuse and high-quality recycling of major 
building elements exiting deconstruction [10]. As for adaptability, i.e., the disposition of a building to transformation; the design usually targets specific client requirements, while future changes in users and context needs are often neglected. As a result, buildings must be heavily modified and sometimes extensively demolished over their lifetime, often before the removed elements have reached their expected service life. This leads to unnecessary social, financial, and environmental costs, while the service life of the whole building and their elements could be optimized by taking future adaptations in the design stage into account.

In addition, a building can adapt more easily and efficiently to changing needs if versatile spaces are designed and demountable building elements are implemented. In 2012, through “Design for Change: Development of an Assessment and Transitional Framework", OVAM-the living lab on circular construction - developed a design and construction strategy based on the principle that our requirements and aspirations concerning built environment will always change, thus introducing the crucial conception that buildings are able to stand change more efficiently.

Considering the enormous materials and waste flows generated when constructing, maintaining, and refurbishing buildings, Design for Change (also known as dynamic building) can play a key role in reducing the environmental impact of the construction industry. Table 1 provides an overview of the Design for Change guidelines, in which the actions are observed both by object (interfaces, sub-components, composition) and by scale (element, building, neighborhood), according to the holistic approach adopted. This provides a comprehensive and clear framework on which a qualitative assessment of both the building design and construction can be based [13].

Table 1. An overview of the Design for Change guidelines.

\begin{tabular}{cccc}
\hline Element & Interfaces & Sub-Components & Composition \\
\hline Building & $\begin{array}{c}\text { Reversibility } \\
\text { Simplicity } \\
\text { Speed }\end{array}$ & $\begin{array}{c}\text { Durability } \\
\text { Reused } \\
\text { Compatibility }\end{array}$ & $\begin{array}{c}\text { Pace-layered } \\
\text { Independence } \\
\text { Prefabrication }\end{array}$ \\
\hline Neighborhood & Accessibility & $\begin{array}{c}\text { Demountability } \\
\text { Reusability } \\
\text { Extensibility }\end{array}$ & Versatility \\
& Adaptable & $\begin{array}{c}\text { Retrofitted } \\
\text { Dimensioned } \\
\text { Removable }\end{array}$ & $\begin{array}{c}\text { Unified } \\
\text { Diverse } \\
\text { Densificable }\end{array}$ \\
\hline
\end{tabular}

Note: Galle W., Vandenbroucke M. (2015).

The key role of rethinking design and the need at all process and product levels thus emerges as an effect driven by both regenerative circular economy principles and the EU's focus on these issues. Tangible goods are obviously the most involved in the changing economy, but services, business models, exchange relationships, and markets should also be redefined and redesigned, as should many further elements. The global economy is showing many fragilities and disruptive technologies which challenge conventional business models. The Ellen MacArthur Foundation defined this revolutionary transformation in the design scope as "Circular design, i.e., improvements in materials selection and product design (standardisation/modularisation of components, purer materials flows, and design for easier disassembly), lie at the heart of a circular economy" [14]. Circular Design requires a wide shift from the current product centered on issues concerning material flows, production processes and conditions, use, and reuse. This need adopts a wide and systemic view, as well as a deep understanding of ecological principles. Compared to other Design for Circularity (DfC) strategies, circular building design is specific to buildings, thus easily compatible with their peculiarities [14]. Circular design can indeed be described as an approach leading to "a building that is designed, planned, built, operated, maintained, and deconstructed consistently with Circular 
Economy principles" [15]. This includes optimizing the buildings' useful lifetime and integrating the end-of-life phase in the design [16]. Circular design challenges the development of products and materials that minimize the use of primary raw materials. As the name implies, the focus of the circular design is on curtailing the value loss of these embedded products by maintaining their circulation in closed loops. These loops, such as reuse, repair, remanufacture, refurbishment, or recycling, extend the product's life cycle and improve resource productivity. As happens in nature, the product, its parts, or constituent materials at the end of their life will so become a resource feeding new cycles of use, within or even outside of the original application scope [17]. A number of studies on Circular Design applied to the construction sector have been carried out in recent years, developing strategies, approaches, and visions that are pushing the transition from sustainable to circular buildings. This is triggering disruptive innovations acting as enablers for the circular economy. In this context, aimed at disseminating knowledge among stakeholders, the Vrije Universiteit Brussel (VUB) project "Le Bâti Bruxellois: Source de nouveaux Matériaux" (BBSM) has collected 16 Circular Design qualities for circular building which give practical support to the designers and all stakeholders in making coherent technical choices. The BBSM research was conducted by VUB (Vrije Universiteit Brussel) Architectural Engineering and was financed by the European Regional Development Fund (ERDF) and the Brussels-Capital Region. Project partners: UCLouvain, Rotor, and Belgian Building Research Institute.

Nine of these features and their related practices are especially helpful in shaping the concept of circular building technologies and in defining added value in Circular Design strategies [18].

The circular design qualities are the following:

- Reused: using building parts and components already present on-site or re-claimed elsewhere;

- Recycled: looking for building components made of low-value by-products or waste materials;

- Renewed: using materials that are replenished continuously by responsible agriculture and forestry;

- Compostable: choosing materials that can be biologically degraded into natural substances;

- Durable: using components that resist the wear and tear of use and reuse;

- Pure: favoring components that consist of a single material instead of a blend;

- Simple: going for low-tech, legible solutions rather than complicated ones;

- Reversible: making it possible to undo connections without damaging joined components;

- Location and site: recognizing and responsibly developing the qualities of a place.

Although less relevant for our purposes, the additional Circular Design qualities of the Belgian study identified are: safe and healthy, manageable, accessible, independent, compatible, multi-purpose, varied.

Circular Design qualities enable more effective reuse, recycling, or renewal of buildings and building components; a proven framework generating added value from the start of the design process onwards, regardless of whether that process adopts a conventional programming scheme, scenario planning, or a co-creation approach [18].

\subsection{Circular Design Strategies: A Growing Concept}

Extending building service life and closing material loops by consistent design choices are the key instruments in transitioning towards a circular construction economy. This requires both an increase in the whole building lifespan and the assurance that all its components can also circulate in endless loops, thus preserving the value as a whole of the resources involved. If properly recovered at the end of its technical, functional, or economic service life, each element can so re-enter a use cycle, being reused for the same or another purpose.

This study refers in particular to three main Circular Design approaches [18,19]:

- Design for Longevity (or Durability): New constructions can be avoided by adopting a circular design and construction practice, which instead focusses on review and up-valuing, upgrading, 
and refurbishing what already exists. Several architectural features can maintain a building's value over time, facilitating maintenance and repair, while enabling the extension of its service life. Among those features, some are related to the estate strategies, such as building location, but many others concern design choices, such as a multi-purpose spatial layout.

- Design for Disassembly and Deconstruction: By adopting this principle, the building elements can be disassembled and each of their components can be easily removed without damage to others. This leads to closing material flows, since components and materials can be recovered using quick and cheap processes, then reclaimed, preserving their value and minimizing waste. Various technical design features, therefore, act as key factors in applying that strategy, such as component durability, assembly methods, and the reversibility of their connections. Since it relies on design purposes such as reversibility, independence, and simplicity of connections and components, Design for Disassembly, often referred to as Reversible Building Design, allows for resource-efficient repairs, maintenance, replacements, as well as the reuse of construction materials, products, and components.

- Design for Reuse: The reclaimed building components and materials can be used again, repaired, remanufactured, or recycled in order to reduce the consumption of virgin, non-renewable resources. To ensure suitability, the elements must be safe and healthy to reuse and made up of a single substance which is easily recycled.

Alternative business models can provide these design approaches with favorable conditions, as shown by the BAMB project, a research action funded by the EU-HORIZON 2020 program which developed the emerging concept of "Buildings as Material Banks". Project BAMB-Buildings as Material Banks-is a consortium of 16 partners from eight European countries (2015/2019). Coordination: Institut Bruxellois pour la gestion de l'environnement-Brussels Instituut Voor Milieubeheer.

Referring to both Design for Disassembly and Design for Reuse strategies applied to the building sector, this new comprehensive approach considers buildings as "material banks", i.e., repositories or stockpiles of valuable, high-quality materials that can be easily taken apart and recovered, having been designed for disassembly.

Since preserving the material value is the key to their circular use, the ways to harvest this value are the circular economy drivers. Instead of disposal, buildings must therefore become banks of valuable materials-slowing down resource withdrawal to a rate compliant with planet restoring capacity. The BAMB project has developed and integrated tools—such as Material Passports and Reversible Building Design schemes-that will enable the shift from static buildings to circular buildings [20]. In order to sprawl the circular building concepts into practice, BAMB also investigated how new circular business models can bring new business opportunities, and how policies, such as data management tools (BIM, Building Information Modelling) and decision-making models can support the implementation of circular building concepts.

\subsection{Circular Technologies for Circular Buildings: Extending Service Life and Closing Material Loops}

For circular technologies there is, at the moment, no recognized definition but, with reference to the Building Design principles applied to Circular Design, the notion of circular building technologies summarises and embodies the need for redefining how materials, processes, and products are designed and used within the circular economy principles [9].

The concept of circular building was introduced by Arup Associates with the prototype designed for the London Design Festival 2016. This was the first building in the UK to comply with circular economy principles while creating a comfortable and aesthetic environment for the user. In order to achieve these goals, designers and engineers worked together to refine the application of a prefabricated construction based on a low-waste, self-supporting, and structurally demountable integrated panel (SIP) wall system, connected to the recycled steel structural frame by reusable clamps. The heat-treated timber for the cladding and decking was sustainably sourced too (Figure 1). 


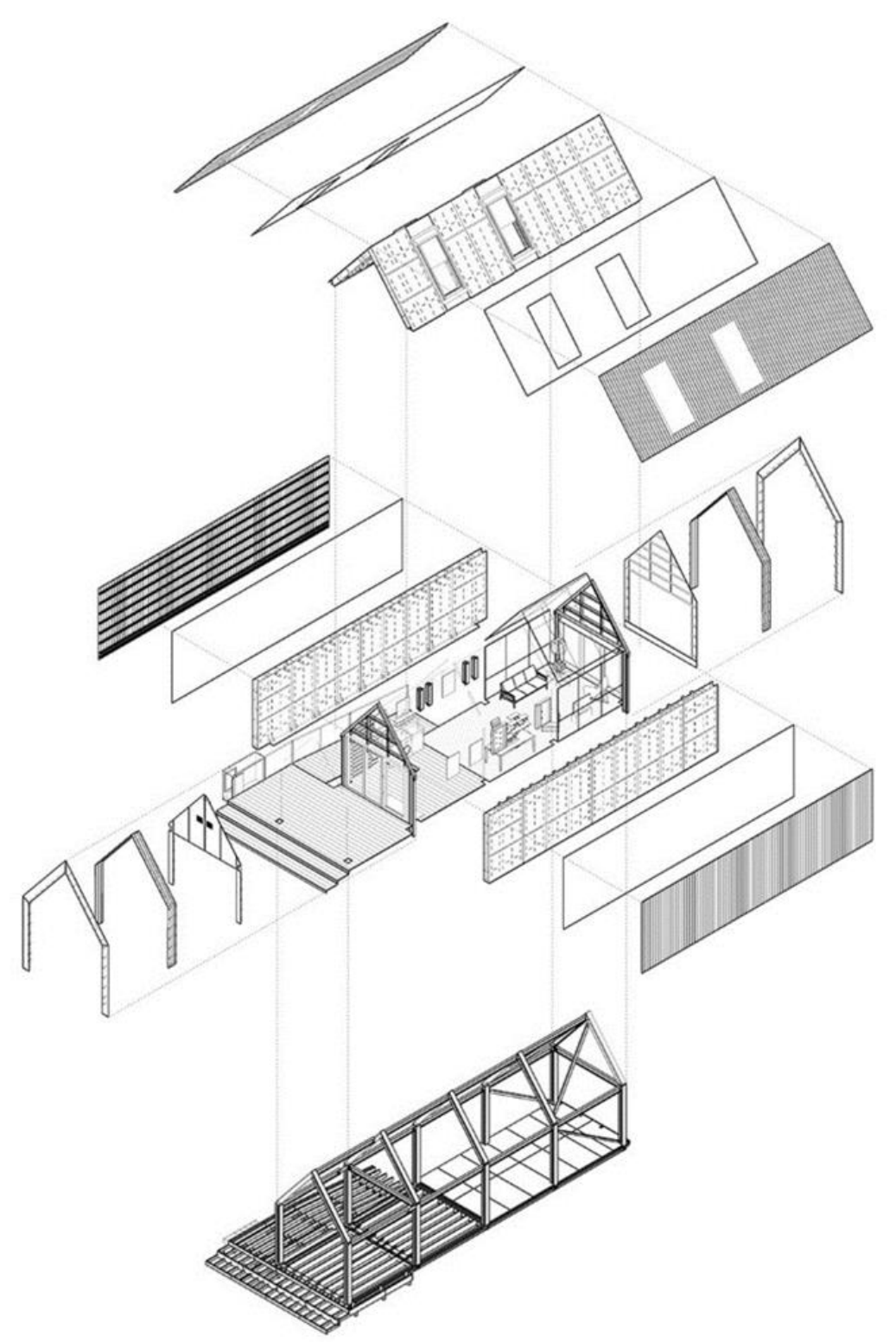

Figure 1. Exploded axonometric of the circular building prototype. Source: @ Arup Associates.

The simple "house-shaped" architecture (which refers to the 6S framework by Stewart Brand) promotes a familiar archetypical geometry at a scale which makes it immediate to perceive (Figure 2). Some definitions of circular building can be found in literature, such as those provided by the Dutch "Agenda for the transition to a circular built environment" or by the Report "A Framework for Circular Buildings: Indicators for possible inclusion in BREEAM" (2018). 


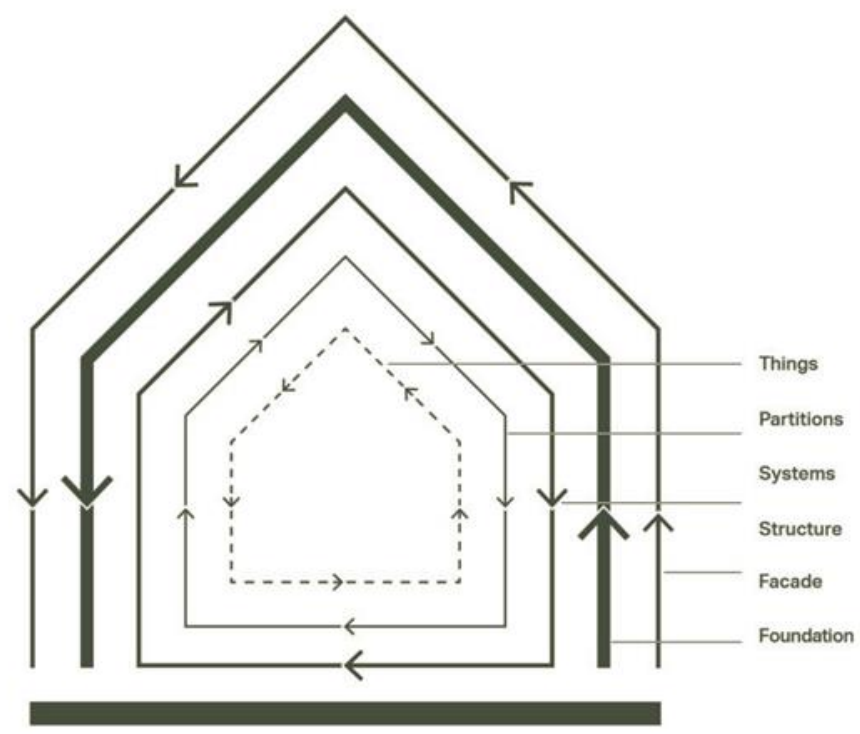

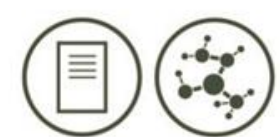

Material passport

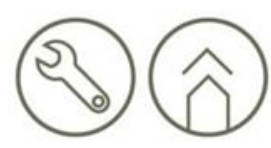

Design for Disassembly

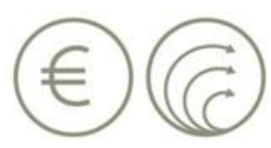

Circular Economy

Figure 2. Reworking of Stewart Brand's Six S's diagram and Circular Design Strategies. Source: @ 3XN_GXN Architects.

A shared description states: "A building that is developed, used and reused without unnecessary resource depletion, environmental pollution and ecosystem degradation. It is constructed in an economically responsible way and contributes to the wellbeing of people and the biosphere. Here and there, now and later. Technical elements are demountable and reusable, and biological elements can also be brought back into the biological cycle" [21].

This is in line with the Ellen MacArthur Foundation's definition of circularity, where the preservation of the building's value and its components is assured by optimizing use and reuse cycles with minimal use of virgin resources. According to the $6 \mathrm{~S}$ framework by Stewart Brand, different layers can be distinguished within a circular building, namely site, structure, skin, space plan, services, and stuff (furnishing and fittings), that are all part of a circular system of products, components, and materials [21]. Unlike circular building, the definition of circular technologies is still not well established but is deduced from the technical and functional specifications of the building in which those technologies are applied, aimed at enhancing the life cycle of each component and implementing circular potential.

According to Kanters [22], Circular buildings could significantly reduce environmental impact and the pressure on natural resources that buildings currently produce, as they are not designed according to circular economy principles. When considering the metrics by which this enhancement may be assessed, most literature focused on the lifecycle analysis of buildings and building materials, but not much is known about the design process of circular buildings [22].

Since design choices strongly jeopardize the subsequent life cycle stages of a building and its components, the role of the design must be questioned within a system that is no longer linear. Although extending service lives is necessary, recycling materials alone does not close all the loops, while more life cycle stages have to be reconnected, leaving virgin material consumption as the last option and avoiding waste production. 
The circular technologies and design choices meeting these requirements are those making it easier to close the material loops. Their main features are summarized below:

- Durability: Since the materials can be only recovered if they remain intact during their use and disassembly, they have to withstand the typical wear and tear of repeated recovery and reuse cycles. Moreover, durable and hardwearing materials often age beautifully, thus maintaining or even increasing their value over time. Choosing the right material at the initial design stage is therefore crucial.

- Compatibility: Building components are compatible if they can be easily reused in different assembling stages, reconfigured, and recombined time and again. The simple geometry of the connection devices, versatile fixing systems, and standardized dimensions are the features maximizing component compatibility to their reuse potential.

- Reversibility: Even durable elements can only be recovered when they can be removed from their location by technically and economically feasible operations. Reversibility describes this requirement; the attitude of a component to be easily disconnected from the building elements that surround them. Dry, mechanic connections such as bolts and screws are thus more effective than wet and chemical joints such as mortar or glue. The high reversibility of the fixings not only allows the recovery of the components at the end of their useful life but also facilitates their maintenance and repair within the operational stage [23].

The notion of service life is in the background of both reversibility and durability features, as it is the time reference which makes the two requirements measurable, also allowing better perception of their qualitative connotations. Due to such complex implications, the service life cannot be established abstractly as just a certain number of expected years of life but must be quantified when planning the intervention by considering the multiple variables affecting it (economic, cultural, etc.), with reference to the process under design. Both scientific literature and regulatory measures often combine terms such as "cost", "efficiency", and "sustainability", which identify the main challenges the building sector is facing today. They are also the main pillars of the ISO 15686 Standard on Buildings and constructed assets, which is included within the service life planning series and provides a comprehensive guide to both service life planning and assessment of building components and systems. The series defines and systematizes methodologies and tools to ensure the most efficient combination of investment, maintenance, and management costs during the life cycle of the building. In particular, it introduces the estimation of service life in the design phase (ISO 15686, Part 2), costs, LCC (ISO15686, Part 5), and environmental impacts in the life cycle (ISO 15686, Part 6) [24].

This is particular for a circular building whose useful life does not end upon its dismantling but will continue through the programmed removal of its constituents feeding the circular process.

By this logic, the convergence of the above-mentioned areas into a single regulatory instrument allows for new ways of operating and critical analysis. It is important to underline, however, that although the main economic and environmental costs are paid during the building management phase, according to the dominant literature, these costs derive from the repeated inability to plan, from the project phase, correct life cycle management.

This highlights the key role that the design phase plays in shaping circular building by implementing effective circular technologies which cause positive effects across the various use cycles of all the involved.

\section{Lack of Innovative Circular Technologies and Indicators for Their Evaluation}

From the analysis of the current literature, it is possible to summarize two main aspects that are particularly relevant: the steady presence of reversibility and durability as a reference point in the current literature concerning Circular Design strategies; and the key role of the Design for extending the service life of buildings and closing material loops. 
From these considerations we wish to highlight:

- The difficulty in finding circular building technologies suitable for enhancing the building's service life and closing material loops;

- The lack of indicators suitable to assess the circular potential of building technologies.

To support the transition to the circular economy, governance, regulations, and business models will play a crucial role. According to the research report Circular Business Models for the Built Environment maximizing value from a circular economy requires several enabling factors. Generally, these fall into three categories-design, information, and collaboration. As a result, additional value will be created through the operation, with benefits for asset value and waste production.

The report explores ways Circular Business Models (CBMs) [7] would provide added benefits throughout the value chain in construction, focusing on three principal models:

- Circular Design Model (development and planning phase of a built asset);

- Circular Use Model (operational phase of an asset);

- Circular Recovery Model (end of the product's service life).

At each stage of a development life cycle, there are opportunities and challenges which need to be addressed. Successful implementation of these business models will require action from designers, suppliers, service providers, contractors, and end-of-life companies by sharing materials, systems, energy, as well as information and services.

The aim of the paper, with particular reference to the Circular Design Model-as opportunities-products, and systems, is that the entire built structure should be designed to last longer with a higher residual value. Therefore, they should be easier to maintain, repair, upgrade, refurbish, remanufacture, or recycle with respect to traditional ones. Additionally, new materials can be developed and sourced, particularly bio-based, that are less resource-intensive or fully recyclable [7]. This highlights that design choices, extending the service life of buildings, and fostering closed material loops can be a key instrument for the transition toward a circular economy [25].

However, suitable evaluation criteria are still lacking, given the limited innovative circular building technologies identified-with reference to the concept previously given as a set of materials, products, and processes [9] — despite the urgent need for their implementation into the circular economy. According to Jawahir and Bradley [26], the technologies that are needed to feed sustainable value in the circular economy have not yet been given due consideration. As a result, expected circular economy benefits are not being achieved. Therefore, a large gap needs to be filled between scarce availability and the large demand for innovative circular technologies, whose expansion is expected in all industries worldwide [27].

Ensuring the successful transition to a circular economy requires, however, measuring circularity through suitable criteria, indicators, and assessment tools [28,29], whose development is still at an early level of definition [30,31]. Ghisellini et al. [32] showed that only 10 out of 155 studies on circular economy strategies include a focus on assessment indicators.

As the circular economy operates on three systemic levels (macro, meso, micro), the tools and indicators for measuring the ircular economy differ depending on the level of application (Su et al., 2013). Among the three levels or scopes at which the circular economy can be observed, some indicators have been developed for the macro-level (global, national, regional, city) and meso-level (industrial symbiosis, eco-industrial parks), while the micro-level (single firm, product) is still largely under-investigated. Although the development of indicators has progressed in recent years, there is currently no standardized way to measure the circularity at a micro-level [33]. According to Kristensen and Mosgaard [34], a detailed understanding of how to measure and document progress toward a circular economy is lacking, especially on a micro-level. This is a barrier for both producers who want to provide circular products and services and for the consumers who want to know how to compare products. The authors reviewed 30 circular economy indicators at the micro-level. The 30 indicators 
found in literature and practice were categorized according to the main focal point(s) of each indicator. This revealed the core circular economy principles considered by the indicators, which enabled analysis of the current scope of circular economy indicators at a micro-level. Nine circular economy categories emerged from this data-driven coding: recycling, remanufacturing, reuse, disassembly, lifetime extension, resource-efficiency, waste management, end-of-life management, and, lastly, multidimensional indicators, which are indicators that do not fall into the other categories as they cover a broader circular economy perspective. The majority of micro-level indicators are developed to assess individual products and materials, and thus function to support decision-making processes in companies.

The conclusion of their study is that there is no shared way of measuring circularity at the micro-level, and this lack is a barrier to further absorption and implementation. The development of standardized criteria suitable for micro-level circularity assessment would be useful, which should be explored either as industry-specific or circular strategy-specific [31].

In line with Kristensen and Mosgaard's study, the paper's focus on micro-level indicators, compared to other levels, is due to the compatibility of the field of application of the nine categories of indicators identified. The field of application of building technologies and their requirements are useful for measuring their circular potential.

\section{Results}

The result confirms the identification and delimitation of indicators that can contribute to the advancement of the state of knowledge which is useful for assessing the circular potential of construction solutions for circular buildings.

This refers to construction solutions that follow the principles of Circular Design, therefore they concern that set of materials, systems, and products, within the principles of the circular economy, summarized as circular building technologies. In particular, they identify and delimit reversibility and durability as possible indicators for assessing circular building technologies suitable for enhancing the building's service life and closing material loops.

The study summarized by this paper aimed to discuss whether reversibility and durability may represent suitable indicators for potential circular building technologies.

A definition is firstly provided of the two terms and their meanings:

- Durability should be understood as the ability of the building system and its materials not to exhibit significant deterioration that implies the loss of functionality for which they were designed. The durability of a building must meet, at least, the working life design, and during this period the necessary maintenance procedures that should be specified for the system must be met [35]. This feature depends on the reliability of the object and its constituents, the environment in which it is placed, and some conditions related to the socio-economic context, such as user behavior. Together, these conditions determine how long the building can properly remain in use.

- Reversibility is a feature or a transforming or dismantling process of a building or parts of it, preserving the maximum integrity of the removed elements and assuring minimum damage to those kept in place [36]. Reversibility, thus, refers mainly to the attitude of easily disassembled systems: this means going back step by step through the building assembly process, recovering most of the elements that had entered the primary process previously. To comply with this requirement, the dismantled element via disassembly must not be disposed of but re-enter into a cycle of use.

Once the requirements are defined, some suitable indicators must be identified to measure the compliance of a technical building configuration. By including these elements within the sustainability protocols, or tools, currently in use, it should be possible to avoid the proliferation of further procedures and better integrate the assessment of circular features within comprehensive and already tested building rating systems. 
This will enhance the effectiveness of those tools in assessing the environmental impact and energy performance of buildings directly from the design phase and whose adoption has been suggested since the early 2000s [37] as part of a necessary integrated approach to accompany technical policies. Since these systems are typically based on a multi-criteria analysis (Criteria Decision Analysis Fines, MCDA), they are set to manage numerous and contrasting variables, which are considered in parallel then fused into an overall score which is very useful to quickly and effectively compare different alternatives. This should allow the addition of some new indicators which specifically refer to circularity requirements, preserving both the structure and the scoring scheme of each rating system. Among the most adopted in current practice, the rating systems based on these principles are LEED (Leadership in Energy and Environmental Design), BREEAM (Building Research Establishment Environmental Assessment Method for Buildings), and SBMethod.

The integration of circularity indicators within the rating system is the third step of this work. It is currently a work in progress whose outcome cannot be made available yet.

\section{Discussion and Conclusions}

The analyzed literature shows great potential for the advancement of knowledge in the field of Circular Design strategies applied to the construction sector, opening several areas of research which are yet to be fully explored with reference to circular building technologies. With regard to this issue, in order to advance knowledge, it is necessary to make a contribution, both to overcome the difficulty in finding circular building technologies suitable for improving the useful life of buildings and to close materials loops; the lack of indicators to assess the circular potential of building technologies. Reversibility and durability, as highlighted in the analyzed studies, are already widely included in all Circular Design strategies, including those addressing the construction sector in particular. Nevertheless, no clear definitions are yet available to link these concepts to indicators suitable for measuring circular economy and, specifically, circular building technologies. The notion of circular building technologies, however, embodies the need to redefine how materials, processes, and products are designed and used within circular economy principles. This absence is a barrier which prevents the extension of circularity assessment of construction technologies to the whole functional complexity of the entire building (circular building). Reversibility and durability can represent reliable indicators for this purpose, as they integrate both quantitative aspects related to circular technologies and qualitative aspects referring to service life and closed loops.

Most literature provides evidence that the building management phase causes most of the economic and environmental costs of the building process due to the recurrent inability to plan an ineffective life cycle management from the design stage. The imperatives of service life and closed loops are key issues which are fundamental for reaching the circular economy targets. They need to be endowed with reliable indicators to allow their assessment and the strengthening of their mutual relationship. Providing micro-level indicators for circular building technologies contributes to the advancement of knowledge on the measurability of circular economy processes, products, and business models applied to the construction sector.

Integrating the sustainable building rating systems currently in use with circular economy indicators, with particular emphasis on reversibility and durability at the micro-level, can provide useful assessment tools to designers to assist their choices early on in the project stages.

Whilst promising, these integrations need further study to develop assessment schemes fit for the operational level, as a wide application of these schemes would accelerate the market penetration of circular building technologies, thus acting as a catalyst for the success of the circular economy.

Author Contributions: Conceptualization, investigation, and data curation, F.G. and M.L.; methodology and formal analysis, E.A.; validation and supervision, A.B.; writing-original draft preparation: for reversibility, E.A.; for durability and service life, M.L.; for circular economy principles, A.B.; for circular building and technologies, F.G.; writing-review and editing, F.G. All authors have read and agreed to the published version of the manuscript. 
Funding: This study did not receive external funding.

Acknowledgments: The authors are grateful to the following contributors for providing copyright permissions for the table and images: Waldo Galle, researcher and policy advisor on sustainability transitions, VUB Architectural Engineering; Arup Associates Europe press office; Tom Castle, 3XN_GXN Architects Business Development Coordinator.

Conflicts of Interest: The authors declare no conflict of interest.

\section{References}

1. OECD. Improving Resource Efficiency and the Circularity of Economies for a Greener World; OECD Environment Policy Papers, No. 20; OECD Publishing: Paris, France, 2020. [CrossRef]

2. Circle Economy. The Circularity Gap Report; Ruparo: Amsterdam, The Netherlands, 2020.

3. Ellen MacArthur Foundation. Towards the Circular Economy: Economic and Business Rationale for an Accelerated Transition Volume 1; Ellen MacArthur Foundation: Cowes, UK, 2013.

4. Den Hollander, M.C. Design for Managing Obsolescence: A Design Methodology for Preserving Product Integrity in a Circular Economy; Delft University of Technology: Delft, The Netherlands, 2018.

5. IEA, UNEP. Global Status Report-Towards a Zero-Emission, Efficient and Resilient Buildings and Construction Sector. 2018. Available online: https:/www.unenvironment.org/resources/publication/ 2019-global-status-report-buildings-and-construction-sector (accessed on 4 July 2020).

6. Eurostat, Generation of Waste by Waste Category, Hazardousness and NACE Rev. 2 Activity [env_wasgen]. Available online: https://appsso.eurostat.ec.europa.eu/nui/show.do?dataset=env_wasgen\&lang=en,2019a (accessed on 20 August 2020).

7. Carra, G.; Magdani, N. Circular Business Models for the Built Environment; BAM CE100; Arup: Bristol, UK, 2017.

8. European Parliament Research Service (EPRS). The Ecodesign Directive: European Implementation Assessment. In Ex-Post Evaluation Unit of the Directorate for Impact Assessment and European Added Value; European Parliament Research Service (EPRS): Brussels, Belgium, 2017.

9. Abbasova, Z. Adopting Circular Innovative Technologies in the Construction Supply Chain of the MRA. Master's Thesis, Tu Delft, Delft, The Netherlands, 2018.

10. European Commission Communication. The European Green Deal, Brussels, 11.12.2019 COM 640 Final. Available online: https://ec.europa.eu/info/sites/info/files/european-green-deal-communication_en.pdf (accessed on 4 July 2020).

11. European Commission. Circular Economy principles for Building Design, 21/02/2020. Available online: https://ec.europa.eu/docsroom/documents/39984 (accessed on 4 July 2020).

12. European Commission Communication. A new Circular Economy Action Plan for a Cleaner and More Competitive Europe, Brussels, 11.03.2020 COM 98 final. 2020. Available online: https:/eur-lex.europa.eu/ legal-content/EN/TXT/DOC/?uri=CELEX:52020DC0098\&from=en (accessed on 9 July 2020).

13. Galle, W.; Vandenbroucke, M. Design for Change: Development of a Policy and Transitional Framework; Summary; OVAM: Mechelen, Belgium, 2015; pp. 3-6.

14. Jelmer, A. A Guidance Tool for Circulr Building Design; Delft University of Technology: Delft, The Netherlands, 2019.

15. Pomponi, F.; Moncaster, A. Circular Economy for the built environment: A research framework. J. Clean. Prod. 2017, 143, 710-718.

16. Leising, E.; Quist, J.; Bocken, N. Circular Economy in the building sector: Three cases and a collaboration tool. J. Clean. Prod. 2017, 176, 976-989. [CrossRef]

17. Fifield, B.; Medkova, K. Circular Design-Design for Circular Economy. In Lahti CleanTech Annual Review; Lahti University of Applied Sciences: Lahti, Finland, 2016.

18. Cambier, C.; Elsen, S.; Galle, W.; Lanckriet, W.; Poppe, J.; Tavernier, I.; Vandervaeren, C. Building a Circular Economy; Vrije Universiteit Brussel VUB Architectural Engineering: Brussel, Belgium, 2019. 
19. Galle, W.; De Temmerman, N.; Vandervaeren, C.; Cambier, C.; Tavernier, I.; Poppe, J.; Elsen, S.; Lanckriet, W.; Verswijver, K. Building a Circular Economy: Design Qualities to Guide and Inspire Building Designers and Clients; VUB-Faculty of Engineering. 2019. Available online: https://www.vub.be/arch/files/circular_design_qualities/VUB\%20Architectural\%20Engineering\% 20-\%20Circular\%20Design\%20Qualities\%20(2019.12).pdf (accessed on 18 June 2020).

20. Durmisevic, E. Reversible Building Design Guideline; BAMB Wp3document; ebook; University of Twente: Enschede, The Netherlands, 2018.

21. DGBC, Metabolic, SGS Search, Circle Economy \& Redevco Foundation. A Framework for Circular Buildings: Indicators for Possible Inclusion in BREEAM; Dutch Green Building Council: The Hague, The Netherlands, 2018.

22. Kanters, J. Circular Building Design: An Analysis of Barriers and Drivers for a Circular Building Sector. Buildings 2020, 10, 77. [CrossRef]

23. Galle, W. Design for Change, towards a Circular Economy (Presentation Handout); Vrije Universiteit Brussel: Brussels, Belgium, 2017.

24. ISO 15686-5:2017. Buildings and Constructed Assets-Service Life Planning Life-Cycle Costing. Available online: https://www.iso.org/obp/ui/\#iso:std:iso:15686:-5:ed-2:v1:en (accessed on 19 June 2020).

25. Galle, W.; Cambier, C.; Denis, F.; Vandervaeren, C.; De Temmerman, N. Dynamic Design Matrix, A Major Review of the Flemish design Principles for Closed MateriSal Loops; Presented at the WASCON Conference, RIL, Tampere; Vrije Universiteit Brussel: Brussels, Belgium, 2018; 14p.

26. Jawahir, I.S.; Bradley, R. Technological Elements of Circular Economy and the Principles of 6R-Based Closed-loop Material Flow in Sustainable Manufacturing. Sci. Procedia CIRP 2016, 40, 103-108. [CrossRef]

27. Baporikar, N. Advances in Business Strategy and Competitive Advantage. In Handbook of Research on Entrepreneurship Development and Opportunities in Circular Economy; IGI Global, Namibia \& University of Pune: Pune, India, 2020; p. 353.

28. Cayzer, S.; Griffiths, P.; Beghetto, V. Design of indicators for measuring product performance in the circular economy. Int. J. Sustain. Eng. 2017, 10, 289-298. [CrossRef]

29. Saidani, M.; Yannou, B.; Leroy, Y.; Cluzel, F.; Kendall, A. A taxonomy of circular economy indicators. J. Clean. Prod. 2019, 207, 542-559. [CrossRef]

30. Giurco, D.; Littleboy, A.; Boyle, T.; Fyfe, J.; White, S. Circular economy: Questions for responsible minerals, additive manufacturing and recycling of metals. Resources 2014, 3, 432-453. [CrossRef]

31. Mesa, J.; Esparragoza, I.; Maury, H. Developing a set of sustainability indicators for product families based on the circular economy model. J. Clean. Prod. 2018, 196, 1429-1442. [CrossRef]

32. Ghisellini, P.; Cialani, C.; Ulgiati, S. A review on circular economy: The expected transition to a balanced interplay of environmental and economic systems. J. Clean. Prod. 2016, 114, 11-32. [CrossRef]

33. Elia, V.; Gnoni, M.G.; Tornese, F. Measuring circular economy strategies through index methods: A critical analysis. J. Clean. Prod. 2017, 142, 2741-2751. [CrossRef]

34. Kristensen, H.S.; Mosgaard, M.A. A review of micro level indicators for a circular economy e moving away from the three dimensions of sustainability? J. Clean. Prod. 2020, 243, 10-17. [CrossRef]

35. Parsekian, G.; Ramos Roman, H.; Silca, C.O.; Santos Faria, M. Concrete Block in Long-Term Performance and Durability of Masonry Structures; Bahman, G., Lourenço, P.B., Eds.; Woodhead Publishing: Cambridge, UK, 2019; pp. 21-57. [CrossRef]

36. Durmisevic, E. Transformable Building Structures: Design for Disassembly as a Way to Introduce Sustainable Engineering to Building Design \& Construction. Ph.D. Thesis, TU Delft University of Technology, Delft, The Netherlands, 2006.

37. European Commission Communication Towards a Thematic Strategy on the Urban Environment, Brussels, 11.02.2004 COM 60 Final. 2004. Available online: https:/www.europarl.europa.eu/meetdocs/committees/ rett/20040316/com_com(2004)0060en.pdf (accessed on 22 July 2020).

(C) 2020 by the authors. Licensee MDPI, Basel, Switzerland. This article is an open access article distributed under the terms and conditions of the Creative Commons Attribution (CC BY) license (http://creativecommons.org/licenses/by/4.0/). 